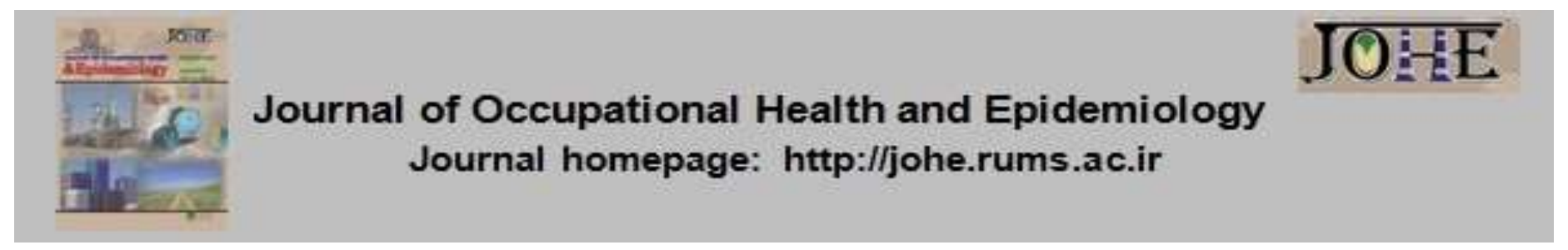

\title{
Job Satisfaction and Psychiatric Morbidity among Resident Doctors in Selected Teaching Hospitals in Southern Nigeria: A web-based Survey
}

\author{
Segun Bello ${ }^{1}$, Rotimi Felix Afolabi², David Ayobami Adewole ${ }^{3}$ \\ 1- PhD in Public Health and Epidemiology, Dept. of Epidemiology and Medical Statistics, Faculty of Public Health, College of \\ Medicine, University of Ibadan, Nigeria. \\ 2- PhD in Medical, Population and Health Research Entity, Faculty of Humanities, North-West University (Mafikeng Campus), South \\ Africa. \\ 3- PhD in Health Management, Dept. of Health Policy \& Management, Faculty of Public Health, College of Medicine, University of \\ Ibadan, Nigeria.
}

Citation: Bello S, Afolabi RF, Adewole DA. Job Satisfaction and Psychiatric Morbidity among
Resident Doctors in Selected Teaching Hospitals in Southern Nigeria: A web-based Survey.
JOHE 2019; 8(4):199-206.

\section{Article Info}

* Corresponding author:

Segun Bello,

E-mail:

drsegunbello@yahoo.com

\section{Article history}

Received: Aug 2019

Accepted: June 2020

10.29252/johe.8.4.199

Print ISSN: 2251-8096 Online ISSN: 2252-0902

Peer review under responsibility of Journal of Occupational Health and Epidemiology

\begin{abstract}
Background: Job satisfaction is a means of contributing to overall life satisfaction and employees' mental health. This study aimed to assess the level of job satisfaction and to determine the association between job satisfaction and psychiatric morbidity.

Materials and Methods: This descriptive study was a web-based survey conducted among 187 resident doctors in four selected teaching hospitals in Southern Nigeria. Data were collected within the time period of August-October, 2018. Job satisfaction was assessed using a single-item satisfaction measure scored on a 5-point Likert scale. In addition, psychological morbidity was assessed using the General Health Questionnaire (GHQ)-12 as the instrument. The Pearson's correlation coefficient and the chi-squared statistic were used to assess the association between job satisfaction and psychological morbidity.

Results: The respondents mean age was $36.5 \pm 5.4$. The majority of them $(60.9 \%)$ were married, $58.1 \%$ were male, and $69.8 \%$ were senior registrars. The mean years of work experience was $9.8 \pm 4.2$. Only $50(26.7 \%)$ respondents expressed overall job satisfaction. The mean score of the GHQ-12 instrument was $14.4 \pm 7.4$ using the Likert scoring scale and $4.0 \pm 3.5$ using the GHQ scoring method. About three-quarters $(76.7 \%)$ and $57.2 \%$ of the participants were probable psychiatric cases when the Likert and GHQ cut-offs were applied, respectively. There was a moderate and significant correlation between job satisfaction scores and scores of the GHQ-12 instrument $(r=-0.5, p=$ $0.01)$.

Conclusion: The respondents demonstrated a low level of job satisfaction and a corresponding high level of psychiatric morbidity.
\end{abstract}

Keywords: Job Satisfaction, Mental Health, Morbidity, Surveys and Questionnaire, Teaching Hospitals, Nigeria.

\section{Introduction}

Work is a broad concept and a poorly defined universal human activity. The satisfaction derived from one's job could be described as an emotional response to the job conditions and a reaction to employees' expectation of what the job should offer to them [1]. This construct has also been described as the degree of personal gratification an employee receives from their work and the pleasure or feeling of accomplishment derived from performing a job well [2]. Though definitions vary, in determining how an individual feels about their job, the interaction between factors intrinsic to the individual, factors intrinsic to the job, and 
factors extrinsic to both the individual and the job could be of considerable importance.

Employers are often preoccupied with how to make people happy at work. Happiness or job satisfaction at work is not an end per se, but it is a means that contributes to overall life satisfaction and employee mental health, thereby leading to organisational productivity. Thus, job satisfaction improves not only the quality of employees' life, but also the quality and quantity of organizational productivity. For example, studies have reported satisfaction impacts among healthcare providers on patient satisfaction and the level of mortality at hospitals [3, 4]. Among all health measures, job satisfaction has been correlated with mental and psychological problems [5].

Several studies have demonstrated the relationship between job satisfaction and good mental health [6-9]. Although these studies have suggested the dependence of psychological health on job satisfaction, emerging evidence suggests that this relationship could be bidirectional, indicating that mental health could affect job satisfaction as well [10]. Since these studies have been mostly cross-sectional, the temporality of exposure could be difficult to ascertain. Research asserts that psychotherapy improved occupational outcomes and job satisfaction measures among depressed workers as clinical symptoms improved; thus, it must be stressed that an improvement in psychological health among workers could positively impact job satisfaction as well [10].

Healthcare workers are known to suffer more psychological distress than workers in other occupations [11]. This is consistent with population measures of psychological health, which showed around a third of doctors scored above the threshold of screening instruments [12]. This could be linked to the nature of clinical work and patients' expectations. Work overload could also play a key role in exacerbating psychological distress among doctors in resource-poor settings with massive shortage of healthcare manpower. According to a Global Health Workforce Statistics report of the World Health Organisation (WHO), a recent increase occurred in brain drain among doctors from sub-Saharan Africa and mainly from Nigeria [13]. It is, therefore, necessary to investigate the job satisfaction level of medical doctors in Nigeria. This research aims to assess the level of job satisfaction among resident doctors in the selected teaching hospitals in Southern Nigeria and to determine the relationship between job satisfaction and psychological health.

\section{Materials and Methods}

This descriptive study was a web-based survey conducted among resident doctors in four selected teaching hospitals in Southern Nigeria. These hospitals included the University College Hospital ((UCH), Ibadan, the University of Calabar Teaching Hospital (UCTH), Calabar, the Ladoke Akintola University of Technology (LAUTECH), Ogbomosho, and the Lagos State University Teaching Hospital (LASUTH), Lagos. The hospitals were not selected randomly, but the selection was based on access to electronic mail addresses of resident doctors obtained with permission from the association executives of local resident doctors with the assurance of absolute confidentiality. The purpose of the survey was fully explained, and the potential participants were informed that the participation was voluntary. In addition, they were assured that the survey was totally anonymised, and that only aggregate data would be used for research purposes. Thus, the survey posed no potential harms to the participants as the data were well anonymised. This study was a full population survey, so it required no sampling or sample size calculation. All 643 resident doctors on the mailing lists were contacted via a link directing the participants to the survey questionnaire.

Although there are multidimensional instruments used to assess job satisfaction, the single-item global measure of job satisfaction gives some psychometric and practical advantages [14]. The single-item approach to job satisfaction measurement was adopted in this study by asking the respondents to rate their overall job satisfaction on a Likert scale of 1-5 with $1=$ very dissatisfied, 2 $=$ dissatisfied, $3=$ neither satisfied nor dissatisfied, $4=$ satisfied, and $5=$ very satisfied. Thus, higher scores indicated greater job satisfaction.

The General Health Questionnaire (GHQ)-12 was utilized in this study to assess psychiatric morbidity in the study population. The GHQ-12 is a short and equally accurate version of the GHQ-60 developed by Goldberg for screening probable non-psychotic psychiatric morbidity in a population [15]. Two of the previously used methods for scoring the GHQ12 were employed in this study, which included the most commonly used GHQ-scoring method (0-0-11) and the Likert scoring method (0-1-2-3). Sum scores of the GHQ-scoring method ranged from 0 12 , while they ranged from $0-36$ in the Likert scoring method. The Likert scoring method is less commonly used, but it offers some psychometric advantages by reducing data skewness [16]. For the GHQ-scoring method, a threshold cut-off of 2/3 was used to identify probable psychiatric cases, 
which was recommended as the most accurate method of screening $[17,18]$. For the Likert scoring method, a threshold cut-off of $8 / 9$ was adopted to identify probable psychiatric cases based on the scoring method [16]. The GHQ-12 has been previously validated in Nigeria with the sensitivity, specificity, and Cronbach's a of $72 \%, 75 \%$, and 0.70 , respectively [19].

Data were managed using SPSS Statistics V.25.0 (IBM Corp. NY, United States). For the analysis of the responses from the GHQ-12, the software included data for only the respondents who answered all items in the GHQ when computing the $\mathrm{GHQ}$ and Likert scores. Thus, in estimating the relationship between job satisfaction and psychological health (the correlation and the chisquared statistic), the number of the included samples was a little less than the total samples for estimating job satisfaction among the respondents. In addition, the reported findings for psychiatric caseness were related to the respondents who reported all items for the GHQ-12. The level of statistical significance was set at $p<0.05$.

\section{Results}

A total of 195 doctors responded to the survey out of the 643 email addresses contacted, which amounted to a response rate of $30.3 \%$. Eight questionnaires were unusable and did not contribute data to the survey; thus, responses from 187 participants were analysed. The respondents' mean age was $36.5 \pm 5.4$, while about $60.9 \%$ aged between $30-39$, 58.1\% were male, and $61.0 \%$ worked at the University College Hospital, Ibadan (Table 1). About three-quarters (76.4\%) of the respondents were married, more than two-thirds of them were senior registrars (69.8\%), and $83.2 \%$ had at least six years of work experience since graduation from the medical school. In addition, the mean number of years of work experience since graduation was $9.8 \pm 4.2$. The most commonly represented specialties included surgery (20.0\%), internal medicine (18.2\%), community medicine (15.3\%), and family medicine (14.7\%).

The distribution of the job satisfaction scores approximated normality, indicating the use of parametric analyses. The mean of the overall job satisfaction score was $2.7 \pm 1.1$. Only $50(26.7 \%)$ respondents expressed they were satisfied (45; $24.1 \%)$ or very satisfied $(5 ; 2.7 \%)$ with their job. Other categories of the responses included neither satisfied nor dissatisfied (55; 29.4\%), dissatisfied $(57 ; 30.5 \%)$, and very dissatisfied $(25 ; 13.4 \%)$.

Table 1. Sociodemographic characteristics of resident doctors in selected teaching hospitals in Southern Nigeria, 2018

\begin{tabular}{|c|c|c|c|}
\hline \multicolumn{2}{|c|}{ Characteristics } & Frequency & Percentage \\
\hline \multirow{3}{*}{ Age group } & $20-29$ & 23 & 12.5 \\
\hline & $30-39$ & 114 & 60.9 \\
\hline & $\geq 40$ & 50 & 26.6 \\
\hline \multirow{2}{*}{ Sex } & Male & 109 & 58.1 \\
\hline & Female & 78 & 41.9 \\
\hline \multirow{3}{*}{ Marital status } & Single & 38 & 20.4 \\
\hline & Married & 143 & 76.4 \\
\hline & Separated/Divorced/Widowed & 6 & 3.2 \\
\hline \multirow{4}{*}{ Institution } & UCH & 114 & 61.0 \\
\hline & UCTH & 20 & 10.8 \\
\hline & LAUTECH & 18 & 9.7 \\
\hline & LASUTH & 35 & 18.5 \\
\hline \multirow{2}{*}{ Position } & Registrar & 56 & 30.1 \\
\hline & Senior registrar & 131 & 69.8 \\
\hline \multirow{9}{*}{ Specialty } & Anaesthesia & 14 & 7.6 \\
\hline & Community medicine & 29 & 15.3 \\
\hline & Family medicine & 28 & 14.7 \\
\hline & Internal medicine & 34 & 18.2 \\
\hline & Obstetrics and Gynaecology & 9 & 4.7 \\
\hline & Ophthalmology & 11 & 5.9 \\
\hline & Paediatrics & 18 & 9.4 \\
\hline & Surgery & 37 & 20.0 \\
\hline & Psychiatry & 8 & 4.1 \\
\hline \multirow{3}{*}{$\begin{array}{l}\text { Total years of work } \\
\text { experience }\end{array}$} & $\leq 2$ & 15 & 7.9 \\
\hline & 3-5 & 17 & 8.9 \\
\hline & $\geq 6$ & 155 & 83.2 \\
\hline
\end{tabular}

Abbreviations:

UCH: University College Hospital, Ibadan; UCTH: University of Calabar Teaching Hospital, Calabar; LAUTECH: Ladoke Akintola University Teaching Hospital, Ogbomosho 
The mean score of the GHQ-12 using the Likert scoring method was $14.4 \pm 7.4$, and it was $4.0 \pm$ 3.5 using the GHQ scoring method. The psychiatric caseness assessed by GHQ scoring cut-off was 91/159 (57.2\%). Psychiatric caseness assessed by Likert scoring cut-off was 122/159 (76.7\%).

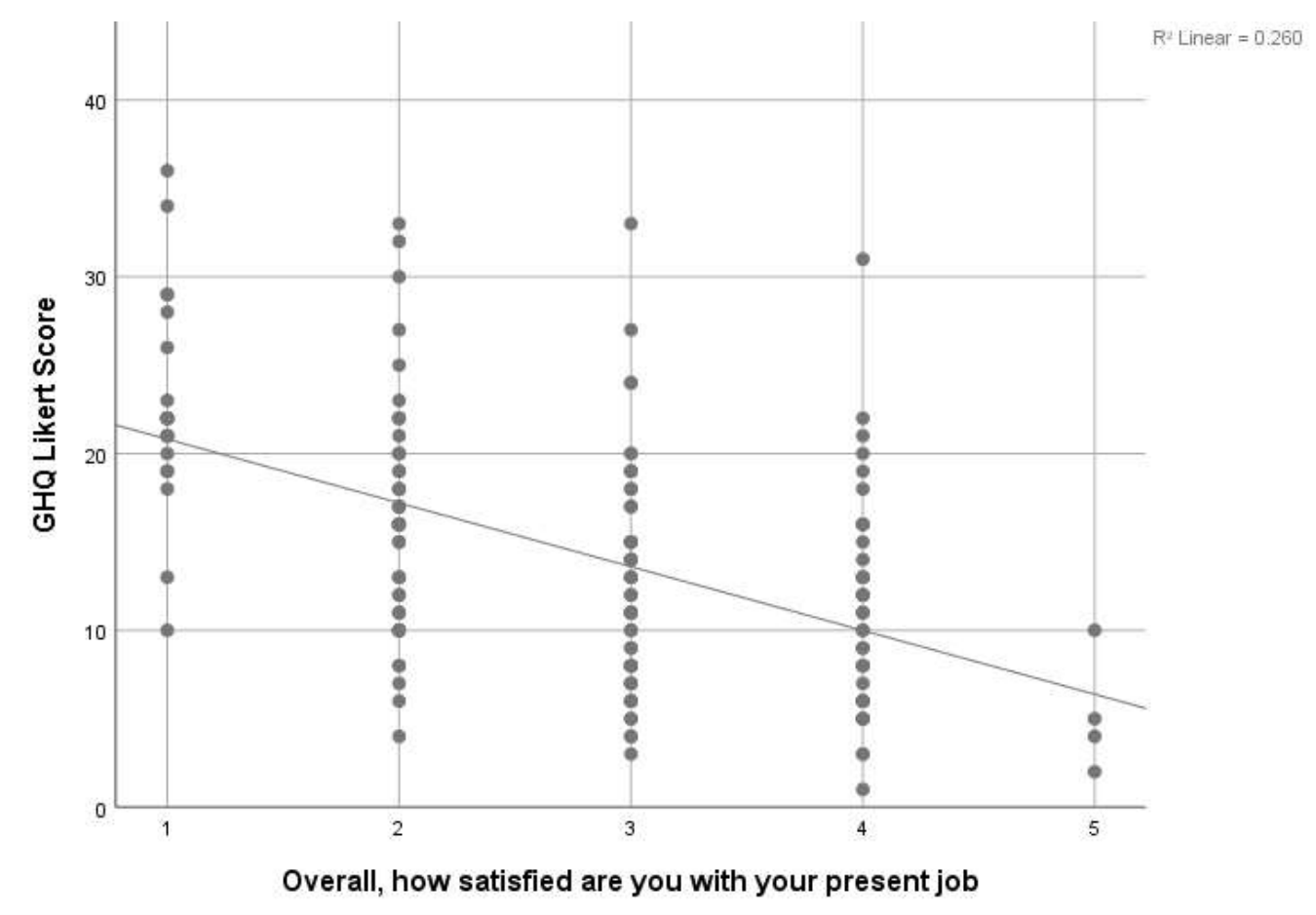

Fig. 1. The scatter plot of the GHQ Likert score versus the overall job satisfaction score with present job among resident doctors in the selected teaching hospitals in Southern Nigeria, 2018

Categories of job satisfaction: 1 = very dissatisfied; 2 = dissatisfied; $3=$ neither satisfied nor dissatisfied; $4=$ satisfied; $5=$ very satisfied

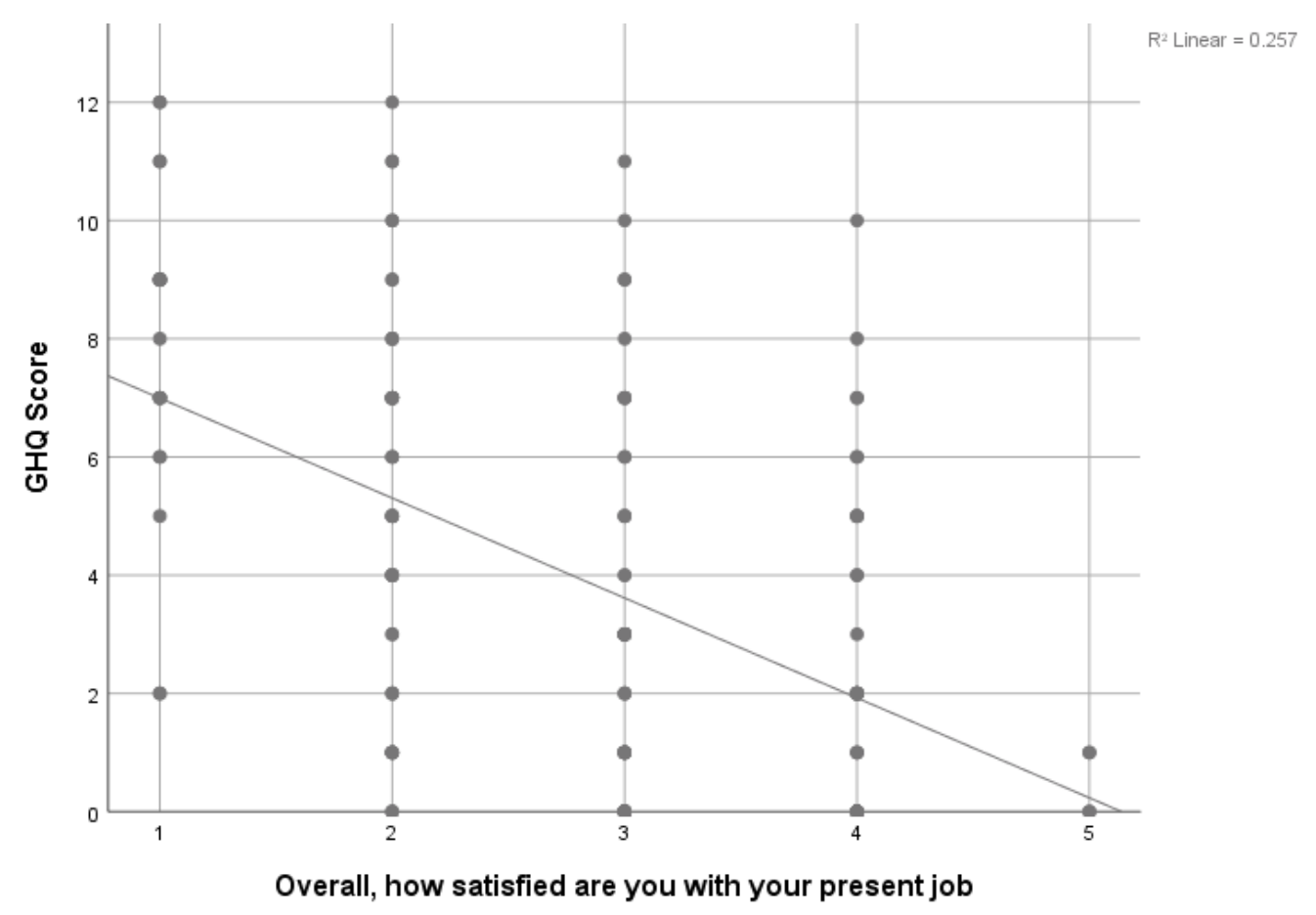

Fig. 2. The scatter plot of the GHQ Score versus the overall job satisfaction score with present job among resident doctors in the selected teaching hospitals in Southern Nigeria, 2018

Categories of job satisfaction: 1 = very dissatisfied; 2 = dissatisfied; $3=$ neither satisfied nor dissatisfied; $4=$ satisfied; $5=$ very satisfied 
Table 2. Job satisfaction and psychiatric caseness (GHQ scores) among resident doctors in the selected teaching hospitals in Southern Nigeria, 2018

\begin{tabular}{cccc}
\hline Satisfaction category & \multicolumn{2}{c}{ Psychiatric caseness } & \multirow{2}{*}{ Total } \\
\cline { 2 - 4 } & Yes & No & $41(100.0 \%)$ \\
\hline Satisfied & $13(31.7 \%)$ & $28(68.3 \%)$ & $50(100.0 \%)$ \\
\hline Neither satisfied nor dissatisfied & $25(50.0 \%)$ & $25(50.0 \%)$ & $68(100.0 \%)$ \\
\hline Dissatisfied & $53(77.9 \%)$ & $15(21.1 \%)$ & $159(100.0 \%)$ \\
\hline Total & $91(57.2 \%)$ & $68(42.8 \%)$ & \\
\hline
\end{tabular}

Chi-square value $=23.9, \mathrm{p}<0.001$

There was a similar moderate and significant negative correlation between job satisfaction scores and scores from both scoring methods, in which Pearson's correlation coefficient $r=-0.510$, $\mathrm{p}=0.01$ (the Likert scoring method), $r=-0.507$, and $p=0.01$ (the GHQ scoring method). The relationships between job satisfaction scores and GHQ scores were illustrated in scatter plots in Figs. 1 and 2. Accordingly, upon an increase in the respondents' job satisfaction scores, the scores of the GHQ-12 decreased. In this respect, r2 was approximately 0.25 , implying that about $25 \%$ of the variations in the GHQ-12 scores could be explained by the linear relationship between the GHQ-12 scores and the job satisfaction scores (Figs. 1 and 2). This was similarly demonstrated in the chi-squared analyses among the three categories of job satisfaction, including satisfied, neither satisfied nor dissatisfied, and dissatisfied as well as the two categories of probable psychiatric cases, i.e. cases and non-cases (Tables 2 and 3). There was also a statistically significant negative relationship between job satisfaction and probable psychiatric caseness. Using GHQ score cut-off, only about a third $(31.7 \%)$ of the satisfied respondents were probable psychiatric cases compared to more than threequarters $(77.9 \%)$ of the respondents who were dissatisfied with their jobs (chi-square $=23.90, p<$ 0.001, Table 2). Likewise, using Likert score cutoff, more than half $(58.5 \%)$ of the satisfied respondents were probable psychiatric cases compared to almost all respondents $(92.6 \%)$ who were dissatisfied with their jobs (chi-square = 19.00, p < 001, Table 3).

Table 3. Job satisfaction and psychiatric caseness (the Likert scoring method) among resident doctors in the selected teaching hospitals in Southern Nigeria, 2018

\begin{tabular}{cccc}
\hline Satisfaction category & Yes & Psychiatric caseness & \multirow{2}{*}{ Total } \\
\cline { 2 - 3 } & $24(58.5 \%)$ & $17(41.5 \%)$ & $41(100.0 \%)$ \\
\hline Satisfied & $16(32.0 \%)$ & $34(68.0 \%)$ & $50(100.0 \%)$ \\
\hline Neither satisfied nor dissatisfied & $63(92.6 \%)$ & $5(7.4 \%)$ & $68(100.0 \%)$ \\
\hline Dissatisfied & $103(64.8 \%)$ & $56(35.2 \%)$ & $159(100.0 \%)$
\end{tabular}

Chi-square $=19.0, p<0.001$

\section{Discussion}

The study showed that only about a quarter of the respondents expressed satisfaction with their jobs, while more than two-thirds of them were at the risk of psychiatric morbidity. The study also showed a moderate negative correlation between job satisfaction and psychiatric morbidity.

The response rate was low, but it was expected from a web-based survey. This cast doubt on the representativeness of the respondents and the generalisability of the survey findings. However, the response rate of about one in three is known to occur in busy professionals, particularly in physicians in online surveys [20-22]. We attempted to improve this rate by sending three different reminders at a two-week interval. Based on this low response rate, the proportion of the satisfied respondents and that of psychiatric caseness should be interpreted cautiously. However, the authors believe that the findings are at best conservative given that the study population appeared to be older and composed of a higher proportion of senior registrars than the population of resident doctors previously studied in Nigeria (Bello et al., 2013; Ofili et al., 2004) [23, 24]. Older ages [7, 25] and higher-level cadres [26] were associated with higher job satisfaction; hence, the findings presented could be considered as a probable overestimate of true job satisfaction, and by extension, an underestimate of true probable psychiatric caseness.

Job satisfaction reported in this study was lower than in similar studies conducted almost a decade ago, which indicated that more than half of the doctors in public hospitals in Calabar were satisfied with their job [23]. During the late 1990s, Ofili et al reported a very low job satisfaction level among doctors in Benin teaching hospital [24]. The study of Ofili et al was conducted towards the end 
of the military rule in Nigeria when job satisfaction was low across many occupational groups in the country; however, Bello et al conducted their study during the democratic rule that witnessed some significant health sector reforms and increased remuneration [23]. The methods of assessment of job satisfaction in previous studies were comparable to the method of assessment in the present study. Accordingly, it appears that job satisfaction among doctors is on a downward trend once again as demonstrated by our findings. This calls for great concerns and may also explain the recent exodus of doctors from Nigeria to the western countries and other destinations in search of greener pastures and job fulfilment. In both previous studies, probable psychiatric caseness was about $20 \%$ or lower for both GHQ and Likert scoring methods. In the same vein, the third study conducted in Bayelsa, Nigeria, about a decade ago reported the psychiatric caseness of about $20 \%$ among doctors and nurses using the GHQ 28 [27]. Although the GHQ 28 version used for all the three previous studies was longer than the one used in this study, evidence demonstrates that both versions are robust and work equally well; thus, one should not expect that it would account for significant deterioration in psychological wellbeing among resident doctors in the present study [28]. The impact of the very low job satisfaction rate on the mental health of the participants appeared to be very huge with an estimate of more than half of the respondents in the present study having been at the risk of psychiatric morbidity. This could pose a considerable risk to patient satisfaction and the quality of healthcare delivery with a potential increase in medical errors and hospital mortality [3, 4].

The correlation between the single-item job satisfaction measure and GHQ scores showed negative linear relationship. Interestingly, the GHQ score categorization of psychiatric caseness demonstrated a classical dose-response relationship as well. Upon a decrease in job satisfaction from the category of satisfied respondents to the category of dissatisfied respondents, the degree of psychiatric caseness increased. This added to the body of empirical evidence showing the positive role of employee job satisfaction in maintaining and improving their mental health status. Findings from several other local and international studies support the relationship between job satisfaction and psychological wellbeing among healthcare providers and in other occupations even with the use of different instruments for job satisfaction and psychological morbidity assessments [6-9].
The Likert categorization of the GHQ appeared to report almost the same proportion of nonpsychiatric cases and the same proportion of satisfied respondents. This might indicate that overall job satisfaction could be a proxy for psychological health assessed on the Likert scoring scale of the GHQ-12. However, the postulation was derived from a pure explorative observation, which requires further research to confirm its accuracy.

\section{Conclusion}

In conclusion, the present study demonstrated a low level of job satisfaction among resident doctors in the four selected tertiary hospitals in Southern Nigeria, with accompanying deterioration in their psychological wellbeing. In addition, psychological health showed a significant negative linear dose-response relationship with job satisfaction. Accordingly, the present level of poor psychological wellbeing among resident doctors was found to be inimical to productivity and patient safety.

\section{Acknowledgement}

This study did not receive any external funding.

Conflict of interest: None declared.

\section{References}

1. Armstrong M. A handbook of human resources management practice. 9th ed. London, United Kingdom: Kogan Page; 2003.

2. Hulin CL, Judge TA. Job attitude: a theoretical and empirical view. In: Borman WC, Ilgen DR, Klimosk RJ, editors. Handbook of psychology. 12. Hoboken, NJ: Wiley; 2003. p. 255-76.

3. Janicijevic I, Seke K, Djokovic A, Filipovic T. Healthcare workers satisfaction and patient satisfaction - where is the linkage? Hippokratia 2013;17(2):157-62.

4. West MA, Guthrie JP, Dawson JF, Borrill CS, Carter M. Reducing patient mortality in hospitals: the role of human resources management. Journal of Organizational Behaviour 2006; 27(7):983-1002.

5. Faragher EB, Cass M, Cooper CL. The relationship between job satisfaction and health: a meta-analysis. Occup Environ Med 2005; 62(2):105-12.

6. Aazami S, Shamsuddin K, Akmal S, Azami G. The Relationship Between Job Satisfaction and Psychological/Physical Health among Malaysian Working Women. Malays J Med Sci 2015; 22(4):40-6.

7. Olatunde BE, Odusanya O. Job satisfaction and psychological well-being among mental health 
nurses. International Journal of Nursing Didactics 2015; 5(8):12-8.

8. Lee MSM, Lee MB, Liao SC, Chiang FT. Relationship between mental health and job satisfaction among employees in a medical center department of laboratory medicine. J Formos Med Assoc 2009; 108(2):146-54.

9. Nadinloyi KB, Sadeghi $H$, Hajloo $N$. Relationship between job satisfaction and employees mental health. Procedia Soc Behav Sci 2013; 84:293-7.

10. Brazilian National Association of Occupational Health, Neto JD, Myung E, Murta G, Vieira A, Lima PR, et al. Depression in the workplace: screening and treatment. Rev Assoc Med Bras 2019; 65(3):295-315.

11. Kim M-S, Kim T, Lee D, Yook J-H, Hong Y-C, Lee S-Y, et al. Mental disorders among workers in the healthcare industry: 2014 national health insurance data. Ann Occup Environ Med 2018; 30:31.

12. Mihailescu M, Neiterman E. A scoping review of the literature on the current mental health status of physicians and physicians-in-training in North America. BMC Public Health 2019; 19(1):1363.

13. Tankwanchi ABS, Ozden C, Vermund SH. Physician emigration from sub-Saharan Africa to the United States: analysis of the 2011 AMA physician masterfile. PLoS Med 2013; 10(9):e1001513.

14. Rose M. Disparate measures in the workplace quantifying overall job satisfaction. Paper presented at: The 2001 British Household Panel Survey Research Conference; 2001 5-7 July; Colchester, UK.

15. Liang $Y$, Wang $L$, Yin $X$. The factor structure of the 12-item general health questionnaire (GHQ$12)$ in young Chinese civil servants. Health Qual Life Outcomes 2016; 14(1):136-.

16. Ruiz FJ, García-Beltrán DM, Suárez-Falcón JC. General Health Questionnaire-12 validity in Colombia and factorial equivalence between clinical and nonclinical participants. Psychiatry Res 2017; 256:53-8.

17. Plummer SE, Gournay K, Goldberg D, Ritter SA, Mann AH, Blizard R. Detection of psychological distress by practice nurses in general practice. Psychol Med 2000; 30(5):1233-7.

18. Shelton NJ, Herrick KG. Comparison of scoring methods and thresholds of the General Health Questionnaire-12 with the Edinburgh Postnatal Depression Scale in English women. Public Health 2009; 123(12):789-93.

19. Makanjuola VA, Onyeama M, Nuhu FT, Kola L, Gureje O. Validation of short screening tools for common mental disorders in Nigerian general practices. Gen Hosp Psychiatry 2014; 36(3):325-9.

20. Cunningham CT, Quan H, Hemmelgarn B, Noseworthy T, Beck CA, Dixon E, et al. Exploring physician specialist response rates to web-based surveys. BMC Med Res Methodol 2015; 15:32.

21. VanGeest JB, Johnson TP, Welch VL. Methodologies for improving response rates in surveys of physicians: a systematic review. Eval Health Prof 2007; 30(4):303-21.

22. Wiebe ER, Kaczorowski J, MacKay J. Why are response rates in clinician surveys declining? Can Fam Physician 2012; 58(4):e225-8.

23. Bello S, Asuzu MC, Ofili AN. Job satisfaction and psychological health of medical doctors in Calabar, southern Nigeria. East Afr Med J 2013; 90(6):189-94.

24. Ofili AN, Asuzu MC, Isah EC, Ogbeide O. Job satisfaction and psychological health of doctors at the University of Benin Teaching Hospital. Occup Med (Lond) 2004; 54(6):400-3.

25. Bogue RJ, Guarneri JG, Reed M, Bradley K, Hughes J. Secrets of physician satisfaction. Study identifies pressure points and reveals life practices of highly satisfied doctors. Physician Exec 2006; 32(6):30-9.

26. Soni K, Chawla R, Sengar R. Relationship between job satisfaction and employee experience. Journal of General Management Research 2017; 4(2):41-8.

27. Rotifa SU, Eguvbe AO, Ofili AN, Adeleye OA. Likelihood of psychological disorder and burnout among doctors and nurses in tertiary health facilities in Bayelsa state, south-south Nigeria. Journal of Primary Health Care and General Practice 2018; 2(2).

28. Bratås $O$, Grønning K, Forbod T. A comparision of two versions of the general health questionnaire applied in a COPD population. Health Care Curr Rev 2014; 2(2).doi: 10.4172/hccr. 1000123 